\title{
Studies on the allostimulatory function of dendritic cells from HCV-HIV-1 co-infected patients
}

\author{
Justin STEBBING*, Steve PATTERSON, Simon PORTSMOUTH, Claire THOMAS, Robert GLASSMAN, \\ Adrian WILDFIRE, Frances GOTCH, Mark BOWER, Mark NELSON, Brian GAZZARD
}

The Department of Immunology, Division of Investigative Science, Faculty of Medicine, Imperial College of Science, Technology and Medicine, The Chelsea and Westminster Hospital, 369 Fulham Road, London SW10 9NH,UK.

\begin{abstract}
There is increasing recognition of the potential morbidity and mortality associated with HIV-1 and hepatitis C (HCV) co-infection. HIV appears to adversely affect HCV disease while the reciprocal effect of HCV on HIV remains controversial. We therefore studied the effect of co-infection on dendritic cell function versus HIV infection alone, as previous work has shown that HCV impairs dendritic cell (DC) function. HIV-1 positive individuals with HCV were matched for CD4 count, HIV-1 RNA viral load and therapy, to HIV-1 positive patients without HCV. Monocyte-derived DC were generated and mixed leukocyte reactions were performed. We assessed allostimulatory capacity with and without administration of exogenous Th1 cytokines, using thymidine uptake and cell division analyses with the vital dye CFSE. We found that monocyte-derived DC from co-infected individuals showed no significant differences in allostimulatory capacity to $e x$ vivo generated DC from HIV-1 infected individuals without HCV. Unlike the situation with HCV infection alone, this impairment was not reversed by increasing concentrations of either interleukin-2 or -12. Monocyte-derived DC from HIV-1 and HCV co-infected individuals have a similar allostimulatory capacity to DC from matched patients with HIV-1 alone. These findings are compatible with results of prior clinical studies that found no evidence that HCV co-infection altered HIV disease progression and has implications for immunotherapeutic approaches in co-infected individuals.
\end{abstract}

Keywords: hepatitis C, HIV, co-infection, dendritic cells.

\section{INTRODUCTION}

Although anti-retroviral therapy has significantly reduced morbidity and mortality as a result of infection with HIV-1 [1], liver disease is an increasingly common cause of death [2-4]. Many of the 200 million individuals infected with hepatitis $\mathrm{C}(\mathrm{HCV})$ and the 50 million individuals infected with HIV are co-infected with both viruses[5-9]. As well as shared routes of transmission, there are many interactions between these small RNA viruses in which infection is often characterised by parenteral transmission followed by a seroconversion illness and then a long latent period lasting many years. HIV-1 infection appears to increase the persistence of the hepatitis $\mathrm{C}$ virus, the level of $\mathrm{HCV}$ RNA and the progression of HCV-related diseases[4,1013]. Exploring potential therapies for $\mathrm{HCV}$ in co-infected patients is a priority.

There are conflicting reports concerning whether HCV infection alters the course of HIV infection[3]. Some studies prior to the advent of highly active anti-retroviral therapy

"Correspondence: Justin STEBBING

Tel: 011-44-208-746-8251, Fax: 011-44-208-746-5997

E-mail: j.stebbing@imperial.ac.uk
(HAART) suggested that survival and progression to AIDS were the same in patients with HCV/ HIV co-infection as in those with HIV alone[14-16], while others suggested an adverse effect[11-17]. In the pre-HAART era, HCV infection was deemed an irrelevance as it was HIV that affected morbidity and mortality. However, with the increased life expectancy of individuals with HIV, HCV has emerged as a problem that adversely affects survival of individuals with HIV $[4,6]$. The hepatotoxicity associated with different HAART regimens also appears to be greater in those with underlying $\mathrm{HCV}$ disease, potentially confounding the ability to provide patients with effective anti-viral therapies [18-21]. There is a need for new, potentially less toxic approaches to treatment.

The immune response often determines the outcome of infection[22, 23]. During infection with HCV and/ or HIV1 , the interactions between the virus and dendritic cells (DC) may contribute to viral persistence, a general feature of both infections[24, 27]. As DC strongly express various capturing, co-stimulatory and adhesion molecules[24, 28], they can activate naive $\mathrm{T}$ cells in a primary response (the only cells that can do so) and measurement of this response is used as a marker of DC function. Furthermore, 
Tab 1. Patient characteristics of matched groups (median and range are shown). Patients were also matched for duration of HAART, the HAART regimen received (either non-nucleoside reverse transcriptase inhibitor containing or protease inhibitor based) and time since seroconversion. No statistical differences between the groups were observed in these parameters.

\begin{tabular}{llcc}
\hline Parameter & $\begin{array}{c}\text { HCV-HIV-1 co-infected } \\
\text { individuals }(\mathrm{n}=10)\end{array}$ & $\begin{array}{c}\text { HIV-1 infected individuals } \\
(\mathrm{n}=10)\end{array}$ & $\begin{array}{c}\mathrm{p} \text { value } \\
\text { (Wilcoxon) }\end{array}$ \\
\hline Age (range) & $37(27-41)$ & $34(26-43)$ & 0.73 \\
CD4 count (cells $\left./ \mathrm{mm}^{3}\right)$ & $398(307-576)$ & $287(146-486)$ & 0.19 \\
CD8 count (cells $\left./ \mathrm{mm}^{3}\right)$ & $1168(675-1369)$ & $958(667-1484)$ & 0.73 \\
Time since HIV-1 seroconversion & 5 years $(3-7)$ & 5.5 years $(3-6)$ & 0.89 \\
HIV-1 RNA viral load (Copies/ml) & $260(<50$ to 16703$)$ & $121(<50$ to 1980$)$ & 0.56 \\
Alanine aminotransferase $(\mathrm{IU} / \mathrm{ml})$ & $52(47-101)$ & $17(11-28)$ & 0.005 \\
Plasma IL-12 $\mathrm{pg} / \mathrm{ml}(\%$ detectable) & 20 & 20 & 1 \\
\hline
\end{tabular}

the ability to generate large numbers of ex vivo DC from peripheral blood progenitors[29] has the potential for use as an immunotherapeutic tool[30].

DC stimulatory capacity must however be assessed in relation to disease status. Three previous studies on this subject have shown that DC recovered from HCV-infected individuals have an impaired capacity to stimulate allogeneic $\mathrm{T}$ cells[31-33] while a more recent investigation showed no differences[34]. One of these studies showed that the exogenous $\mathrm{T}_{\mathrm{h}} 1$ cytokines interleukin-2 (IL-2) and IL-12 reversed and restored the low allogeneic $\mathrm{T}$ cell proliferation observed with monocyte-derived DC from individuals with chronic HCV infection alone[32]. Other studies have demonstrated that HIV-1 not only impairs the function of DC [35] (H Donaghy pers commun.) but also that HIV-1 can inhibit IL-12 secretion from these cells[36, 37]. HIV-1 and HCV co-infection may therefore be expected to significantly impair function precluding the use of this 'easy-to-generate' immune cell subset in immunotherapeutic approaches. We therefore assessed the primary stimulatory capacity of monocyte-derived DC from chronically infected individuals, with both HIV-1 and HCV and HIV-1 alone, in order to establish whether such stimulatory capacity was further impaired.

\section{MATERIALS AND METHODS}

\section{Participants and generation of DC}

Consenting HIV-1-seropositive patients with $(n=10)$ and without $(\mathrm{n}=10)$ chronic untreated HCV (genotype $1 \mathrm{a} / \mathrm{b})$ were enrolled in this study. These were matched for immune (CD4, CD8 count), virologic parameters, HAART and time on HAART (Tab 1) in order to enable comparisons between the two patient groups. Those without $\mathrm{HCV}$ were confirmed as being HCV antibody negative (Abbot IMX system, Maidenhead, UK) and individuals who were HCV antibody positive were further defined by PCR (Roche Amplicor, Mannheim, Germany). Patients receiving therapies other than HAART including interferon- $\alpha$ and ribavarin were excluded, as were those with chronic hepatitis B. All volunteers were from the Chelsea and Westminster Hospital, London, voluntary written informed consent was provided and the study received appropriate ethical approval.

Blood from all individuals was processed within $1 \mathrm{~h}$ from drawing, no freezing occurred and all reagents used were selected for their low levels of endotoxin contamination. Peripheral blood mononuclear cells (PBMC) were separated on a Ficoll-Histopaque density gradient and resuspended in RPMI 1640 medium supplemented with $10 \%$ heat-inactivated FCS, L-glutamine, and streptomycin/ penicillin prior to further separation by centrifugation over $50 \%$ Percoll. Monocyte-derived DC were propagated from PBMC using a previously described protocol[29]. Briefly, PBMC were incubated on gelatinecoated flasks for $2 \mathrm{~h}$ at $37^{\circ} \mathrm{C}$, nonadherent cells were removed, and fresh medium supplemented with $800 \mathrm{U} / \mathrm{ml} \mathrm{rhGM-CSF}$ and $800 \mathrm{U} / \mathrm{ml}$ rhIL-4 was added. Cells were incubated for $6 \mathrm{~d}$ at $37^{\circ} \mathrm{C}$ at $5 \% \mathrm{CO}_{2}$. Half the volume of the medium was removed on alternate days and replaced with fresh medium supplemented with the GM-CSF and IL-4 (Sigma, Poole, UK).

\section{Cellular assays}

Mixed leukocyte reactions (MLR) to assess the stimulatory capacity of DC were performed as described[38]. Fresh PBMCs were isolated from healthy HIV seronegative controls for use as responders and these were cultured in triplicate at $10^{5} /$ well for $5 \mathrm{~d}$ with a maximum of $1 \times 10^{4} /$ well stimulator cells (monocyte-derived DC from patients) in 96-well round-bottomed plates in $200 \mu \mathrm{l}$ medium. Five doubling dilutions of stimulators were made. Recombinant human IL-12 and IL-2 (Sigma, Poole, UK) were added to a final concentration of $10-100 \mathrm{U} / \mathrm{ml}$ and $10-50 \mathrm{ng} / \mathrm{ml}$ respectively. Addition of TNF- $\alpha$ (Sigma) at $10 \mathrm{ng} / \mathrm{ml}$ occurred when described at $24 \mathrm{~h}$. Cultures were pulsed with $\left({ }^{3} \mathrm{H}\right) \mathrm{TdR}(1 \mu \mathrm{Ci} /$ well; Amersham, Freiberg, Germany) at $5 \mathrm{~d}$ for $16 \mathrm{~h}$. Nuclei were harvested onto fiberglass filter paper (Packard Instrument, Meriden, CT) and radioactivity in the filter paper was quantified as cpm by use of a direct beta counter 9600 (Packard Instrument).

In order to ascertain that any defect we observed in stimulatory capacity resided in the DC themselves and not in the T cells, we reversed this procedure and performed MLR experiments to assess the stimulatory capacity of monocyte-derived DC from uninfected volunteers using allogeneic $\mathrm{T}$ cells from co-infected individuals as responders (i.e. normal stimulators with 'co-infected' responders). 
IL-12 levels were also analysed in the plasma of patients and also in MLR supernatants (from day 4 as previously described[32]) using an ELISA kit for IL-12 p70 (R\&D systems, Abingdon, UK) with a detection threshold of $3 \mathrm{pg} / \mathrm{ml}$.

Results of MLRs were expressed as stimulation index (SI) determined as mean cpms in cultures containing responding and stimulator cells divided by mean cpms in culture containing responder cells alone or as $\triangle \mathrm{CPM}$ determined as mean cpms minus the appropriate background. At each number of stimulating DCs between HCV/ HIV infected patients and HIV-matched controls, comparisons were made using the Wilcoxon test. As it was deemed necessary to perform comparisons at each stimulator number, $\mathrm{p}$ values were adjusted using the Bonferroni correction.

Labelling with 5-(and 6-) carboxy fluoroscein diacetate succimidyl ester (CFSE; Molecular probes, Eugene, USA) to quantitate cell division was performed by suspending a final concentration of $10 \mu \mathrm{M}$ with $2 \times 10^{7} \mathrm{PBMC} / \mathrm{ml}[39,40]$. After incubation at $37^{\circ} \mathrm{C}$ for $10 \mathrm{~min}$, the staining reaction was quenched by the addition of a large volume of ice-cold PBS followed by 2 washes in the same medium. Analysis of cell division was performed after $5 \mathrm{~d}$ MLRs for 2 patients in each group using a Becton Dickinson FACS caliber with a minimum of 100,000 cells acquired in the live gate. Plasma HIV-1 viral loads were determined by the Bayer HIV-1 RNA 3.0 (bDNA) Assay (Berkshire, UK) or by PCR assay (Cobas Amplicor HIV-1 Monitor test version 1.5 , Roche Diagnostics, UK) with a lower level of detection $<50$ HIV-1 RNA copies/ml. Absolute CD4 and CD8 counts were obtained by flow cytometry (BeckmanCoulter, Oxford, UK).

\section{RESULTS AND DISCUSSION}

Here, the allogeneic or primary stimulatory capacity of DC derived from HIV-1 and HCV co-infected individuals is similar to that observed in DC from HIV-1 infected individuals alone. We observed no statistically significant differences at any ratio of stimulator DC to responder PBMC (using either counts per minute or stimulation index, Fig 1).

In these matched individuals, the addition of a range of concentrations of the exogenous $\mathrm{T}_{\mathrm{H} 1}$ cytokines, IL-2 or IL-12, did not increase allostimulatory capacity. However, the administration of TNF- $\alpha$ did result in a similar increase in both groups studied. This is compatible with its role in switching DC from an antigen capturing to an antigen presenting function[23, 41].

In our co-infected and HIV-1 infected cohorts, there were no statistically significant differences in HIV-1 RNA copies/ml, CD4 count or CD4 percent, CD3, CD8, CD16/ 56 (natural killer) and CD19 (B cell) counts between the groups. We did however observe a significantly higher ALT in the co-infected individuals (Tab 1). There were no significant correlations between these immunologic counts (Pearson's correlation co-efficient, $\mathrm{r}=0.01-0.1$ ) or HIV-1 viral load $(r=0.1)$ and the peaks of thymidine uptake.

The non-significant trend towards a decrease in allogeneic stimulation in coinfected patients seen in the MLRs was confirmed using CFSE, a vital dye that is cleaved


Fig 1. Matched patient comparisons: the allostimulatory capacity of DC derived from the two groups of patients studied is shown with HCV-HIV-1 co-infected individuals (dashed line) versus HIV-1 infection alone (solid line). The medians and interquartile ranges are shown. Both graphs show ${ }^{3} \mathrm{H}$-thymidine incorporation by allogeneic T cells cultured with DC from HCV PCR positive $(n=10)$ or negative $(\mathrm{n}=10)$ patients in MLR. The upper graph demonstrates the counts per minute and the lower demonstrates the counts per minute divided by the background.

once inside cells rendering its membrane impermeable before it segregates equally in daughter progeny (Fig 2). While we demonstrated that the CFSE label was less rapidly lost and less divisions occurred in response to stimulation of DC derived from individuals with HCV-HIV co-infection compared to HIV-1 seropositive controls, we confirmed that there were no statistically significant differences. Using thymidine uptake as a quantitative measure, we have however established that if the trend towards a minimal decrease in allogeneic capacity in co-infection continued in the same direction, more than 100 patients would require recruiting to demonstrate any significant difference. This is compatible to work that we have performed demonstrating no significant differences between levels of the DC co-stimulatory molecules (CD40, CD80, CD83 and CD86) in the matched groups (data not shown).

In order to confirm that the defect resided in the DC but not in responding T cells, we performed MLRs using healthy volunteer monocyte-derived DC with T cells obtained from patients with co-infection: results showed no differences to MLRs using T cells from normal responders. ELISAs performed to measure IL-12 in patients' plasma and in MLR supernatant showed no significant changes between groups and were generally unrevealing.

As mentioned, the clinical data on whether HCV infection 
A HCV and HIV-1 co-infection


B



HIV-1 infection



Fig 2. CFSE staining of allogeneic $\mathrm{T}$ cells followed by stimulation with monocyte-derived DC from representative individuals in the matched groups. Black arrows above the first dot plot correspond to a cell division[40]. Shown are dot plots and histograms from, (A) HCV-HIV-1 co-infection, (B) HIV-1 infection alone.

alters the natural history of HIV infection are conflicting. From a large cohort of HIV-infected individuals in Switzerland, Greub et al reported that HCV seropositivity increased the likelihood of progression to a new AIDSdefining clinical event or death with a median of 28 months of follow-up[42]. However, this decrease in survival did not appear to be due to a reduced responsiveness of patients with co-infection to HAART, since there was no association between HCV seropositivity and probability of reaching an HIV RNA level below 400 copies per ml. The increase in $\mathrm{CD} 4$ cell count in response to antiretroviral therapy did appear to be less in patients with HCV infection than in those with HIV alone, however. The authors hypothesised that HCV could have a direct pathogenic effect on lymphocytes, impairing the recovery of HIV-related immune function with antiretroviral therapy, thus, explaining both the progression to AIDS and the delay in CD4 cell count recovery in patients with $\mathrm{HCV}$. Other recent studies have reported similarly compromised CD4 cell responsiveness in HIV-HCV infected individuals despite HIV RNA suppression[43]. Supporting this, HCV replication in lymphoid cells has been shown in HIV-1 positive patients[44].

More recently, Sulkowski et al. showed no difference in the risk of death or in the risk of developing a new
AIDS-defining illness in patients with and without HCV [45]. Survival was reduced in HCV-infected patients with baseline CD4 cell counts from 50 cells $/ \mathrm{mm}^{3}$ through 200 cells $/ \mathrm{mm}^{3}$, but this difference was not sustained in a multivariate model that included an adjustment for HAART. Patients with HCV infection had an increased but nonsignificant likelihood of progression to a CD4 cell count below 200 cells $/ \mathrm{mm}^{3}$; this association between CD4 cell count and $\mathrm{HCV}$ infection was not demonstrated in a multivariate regression analysis. Thus, this clinical cohort study and our data suggests that $\mathrm{HCV}$ does not play a direct role in altering HIV disease progression or in subverting the responses of HIV infected dendritic cells, but rather that the management of patients with HIV infection is being compromised by coexisting $\mathrm{HCV}$ infection. Differences in survival in HCV-positive and HCV-negative patients observed in the European study[42] were likely not due to differences in antiretroviral therapy, since the adverse effect of $\mathrm{HCV}$ was even seen in patients with well-controlled HIV infection on therapy[45]. Different outcomes observed may simply be due to differences in the demographics of the study populations. However, the progression from HIV infection diagnosis to AIDS has been shown to be similar in HIV-infected versus co-infected populations in other cohorts, supporting the lack of a direct effect of $\mathrm{HCV}$ on HIV immune progression[46]. While we have identified $\mathrm{HCV}$ replication in DC from co-infected patients (C Thomas, pers commun), their function does not appear further impaired.

As co-infection does not appear to lead to an additional impairment in allostimulatory capacity (compared to $\mathrm{HCV}$ alone or HIV-1 alone), DC derived immunotherapeutic approaches being developed for HIV[30, 47] could also be used to target co-infected individuals. Monocyte-derived DC could constitute a readily available source of potent antigen-presenting cells and be used to stimulate naive CD4 and CD8 T cell-mediated responses in HIV+ patients or to enhance the reactivity of secondary memory $\mathrm{T}$ cells to HIV and non-HIV (including HCV) antigens.

\section{ACKNOWLEDGMENTS}

We are grateful to the study participants and also to Joedy Wilkinson and Louise Campbell for help obtaining blood. We would also like to thank Sundhiya Mandalia for help with statistical analysis.

Received, Oct 14, 2003

Revised, Apr 20, 2004

Accepted, Apr 22, 2004

\section{REFERENCES}


1 Palella FJ, Jr, Delaney KM, Moorman AC, et al. Declining morbidity and mortality among patients with advanced human immunodeficiency virus infection. HIV Outpatient Study Investigators. N Engl J Med 1998; 338:853-60.

2 McGovern B, Bica I. Risk of HAART therapy in hepatitis C. Hepatology 2002; 35:730.

3 Rossi SJ, Volberding PA, Wright TL. Does hepatitis C virus infection increase the risk of HIV disease progression? Jama 2002; 288:241-3.

4 Rosenthal E, Poiree M, Pradier C, et al. Mortality due to hepatitis C-related liver disease in HIV-infected patients in France (Mortavic 2001 study). Aids 2003; 17:1803-9.

5 Maier I, Wu GY. Hepatitis C and HIV co-infection: a review. World J Gastroenterol 2002; 8:577-9.

6 Gervais A. [Chronic hepatitis C in HIV-HCV co-infected patients]. Gastroenterol Clin Biol 2002; 26 Spec No 2:B121-32.

7 Mohsen AH, Easterbrook P, Taylor CB, Norris S. Hepatitis C and HIV-1 co-infection. Gut 2002; 51:601-8.

8 Roca B, Suarez I, Gonzalez J, et al. Hepatitis C virus and human immunodeficiency virus co-infection in Spain. J Infect 2003; 47: 117-24.

9 Strasfeld L, Lo Y, Netski D, Thomas DL, Klein RS. The association of hepatitis $\mathrm{C}$ prevalence, activity, and genotype with HIV infection in a cohort of New York City drug users. J Acquir Immune Defic Syndr. 2003; 33:356-64.

10 Darby SC, Ewart DW, Giangrande PL, et al. Mortality from liver cancer and liver disease in haemophilic men and boys in UK given blood products contaminated with hepatitis C. UK Haemophilia Centre Directors' Organisation. Lancet 1997; 350: 1425-31.

11 Lesens O, Deschenes M, Steben M, Belanger G, Tsoukas CM. Hepatitis $\mathrm{C}$ virus is related to progressive liver disease in human immunodeficiency virus-positive hemophiliacs and should be treated as an opportunistic infection. J Infect Dis 1999; 179: 1254-8.

12 Thomas DL, Astemborski J, Rai RM, et al. The natural history of hepatitis $\mathrm{C}$ virus infection: host, viral, and environmental factors. Jama 2000; 284:450-6.

13 Monga HK, Rodriguez-Barradas MC, Breaux K, et al. Hepatitis $\mathrm{C}$ virus infection-related morbidity and mortality among patients with human immunodeficiency virus infection. Clin Infect Dis 2001; 33:240-7.

14 Quan CM, Krajden M, Grigoriew GA, Salit IE. Hepatitis C virus infection in patients infected with the human immunodeficiency virus. Clin Infect Dis 1993; 17:117-9.

15 Wright TL, Hollander H, Pu X, et al. Hepatitis C in HIV-infected patients with and without AIDS: prevalence and relationship to patient survival. Hepatology 1994; 20:1152-5.

16 Dorrucci M, Pezzotti P, Phillips AN, Lepri AC, Rezza G. Coinfection of hepatitis $C$ virus with human immunodeficiency virus and progression to AIDS. Italian Seroconversion Study. J Infect Dis 1995; 172:1503-8.

17 Sabin CA, Telfer P, Phillips AN, Bhagani S, Lee CA. The association between hepatitis $\mathrm{C}$ virus genotype and human immunodeficiency virus disease progression in a cohort of hemophilic men. J Infect Dis 1997; 175:164-8.

18 Macias J, Melguizo I, Fernandez-Rivera FJ, et al. Mortality due to liver failure and impact on survival of hepatitis virus infections in HIV-infected patients receiving potent antiretroviral therapy. Eur J Clin Microbiol Infect Dis 2002; 21:775-81.

19 Sulkowski MS, Thomas DL, Mehta SH, Chaisson RE, Moore RD. Hepatotoxicity associated with nevirapine or efavirenz-containing antiretroviral therapy: role of hepatitis $\mathrm{C}$ and $\mathrm{B}$ infections. Hepatology 2002; 35:182-9.

20 Sulkowski MS. Hepatotoxicity Associated with Antiretroviral Therapy Containing HIV-1 Protease Inhibitors. Semin Liver Dis. 2003; 23:183-94.

21 Kontorinis N, Dieterich DT. Toxicity of non-nucleoside analogue reverse transcriptase inhibitors. Semin Liver Dis 2003; 23: 173-82.

22 Siegal FP, Spear GT. Innate immunity and HIV. Aids 2001;15 Suppl 5:S127-37.

23 Stebbing J, Gazzard B, Portsmouth S, et al. Disease associated dendritic cells respond to disease-specific antigens through the common heat shock protein receptor. Blood 2003; 15:15

24 Stahl-Hennig C, Steinman RM, Tenner-Racz K, et al. Rapid infection of oral mucosal-associated lymphoid tissue with simian immunodeficiency virus. Science 1999; 285:1261-5.

25 Chougnet C, Shearer GM, Landay AL. The Role of Antigenpresenting Cells in HIV Pathogenesis. Curr Infect Dis Rep 2002; 4:266-71.

26 Knight SC. Dendritic cells and HIV infection; immunity with viral transmission versus compromised cellular immunity? Immunobiology 2001; 204:614-21.

27 Sewell AK, Price DA. Dendritic cells and transmission of HIV-1. Trends Immunol 2001; 22:173-5.

28 McDonald D, Wu L, Bohks SM, KewalRamani VN, Unutmaz D, Hope TJ. Recruitment of HIV and its receptors to dendritic cell-T cell junctions. Science $2003 ;$ 300:1295-7.

29 Sallusto F, Lanzavecchia A. Efficient presentation of soluble antigen by cultured human dendritic cells is maintained by granulocyte/macrophage colony-stimulating factor plus interleukin 4 and downregulated by tumor necrosis factor alpha. J Exp Med 1994; 179:1109-18.

30 Lu W, Wu X, Lu Y, Guo W, Andrieu JM. Therapeutic dendriticcell vaccine for simian AIDS. Nat Med 2003; 9:27-32.

31 Hiasa Y, Horiike N, Akbar SM, Set al. Low stimulatory capacity of lymphoid dendritic cells expressing hepatitis $\mathrm{C}$ virus genes. Biochem Biophys Res Commun 1998; 249:90-5.

32 Kanto T, Hayashi N, Takehara T, et al. Impaired allostimulatory capacity of peripheral blood dendritic cells recovered from hepatitis C virus-infected individuals. J Immunol 1999; 162:5584-91.

33 Bain C, Fatmi A, Zoulim F, Zarski JP, Trepo C, Inchauspe G. Impaired allostimulatory function of dendritic cells in chronic hepatitis C infection. Gastroenterology 2001; 120:512-24.

34 Longman RS, Talal AH, Jacobson IM, Albert ML, Rice CM. Patients chronically infected with hepatitis $\mathrm{C}$ virus have functional dendritic cells. Blood 2003; 2:2.

35 Knight SC, Macatonia SE, Patterson S. HIV-1 infection of dendritic cells. Int Rev Immunol 1990; 6:163-75.

36 Chehimi J, Starr SE, Frank I, et al. Impaired interleukin 12 production in human immunodeficiency virus-infected patients. J Exp Med 1994; 179:1361-6.

37 Chambers KA, Parato KG, Angel JB. Active cellular infection of myeloid cells is required for HIV-1-mediated suppression of interleukin-12 p40 expression. Cell Immunol 2002; 215:120-32.

38 Young JW, Steinman RM. Accessory cell requirements for the mixed-leukocyte reaction and polyclonal mitogens, as studied 
with a new technique for enriching blood dendritic cells. Cell Immunol 1988; 111:167-82.

39 Fulcher D, Wong S. Carboxyfluorescein succinimidyl ester-based proliferative assays for assessment of $\mathrm{T}$ cell function in the diagnostic laboratory. Immunol Cell Biol 1999; 77:559-64.

40 Langenkamp A, Messi M, Lanzavecchia A, Sallusto F. Kinetics of dendritic cell activation: impact on priming of TH1, TH2 and non-polarized T cells. Nat Immunol 2000; 1:311-6.

41 Banchereau J, Paczesny S, Blanco P, et al. Dendritic cells: controllers of the immune system and a new promise for immunotherapy. Ann N Y Acad Sci 2003; 987:180-7.

42 Greub G, Ledergerber B, Battegay M, et al. Clinical progression, survival, and immune recovery during antiretroviral therapy in patients with HIV-1 and hepatitis C virus co-infection: the Swiss HIV Cohort Study. Lancet 2000; 356:1800-5.

43 Rimland D, Guest JL, Anderson KB. The effect of hepatitis C co-infection on survival in the HIV Atlanta VA Cohort Study in the post HAART era. CROI. Seattle: Abstract 658-M; 2002.

44 Laskus T, Radkowski M, Piasek A, et al. Hepatitis C virus in lymphoid cells of patients co-infected with human immunodeficiency virus type 1: evidence of active replication in monocytes/ macrophages and lymphocytes. J Infect Dis 2000; 181:442-8.

45 Sulkowski MS, Moore RD, Mehta SH, Chaisson RE, Thomas DL. Hepatitis C and progression of HIV disease. Jama 2002; 288:199-206.

46 Law P, Duncombe C, Dore G. Impact of viral hepatitis co-infection on the response to antiretroviral therapy among a cohort of Thai HIV-infected patients enrolled in HIV-NAT trials. CROI Seattle; 2002.

47 Lisziewicz J, Rosenberg E, Lieberman J, et al. Control of HIV despite the discontinuation of antiretroviral therapy. N Engl J Med 1999; 340:1683-4. 